\title{
SEPARATE ASSESSMENT OF GLUTEUS MEDIUS AND MINIMUS: B -MODE OR M-MODE ULTRASOUND?
}

Angela V. Dieterich, PT a , Louise Deshon, AMS ${ }^{\text {b }}$, Christine M. Pickard, PhD ${ }^{a}$, Geoffrey R. Strauss, MPE ${ }^{a}$, Janice McKay, $\mathrm{PhD}^{\mathrm{b}}$

${ }^{*}$ A. Dieterich, Curtin University, School of Physiotherapy and Exercise Science, GPO Box U1987, Perth, WA 6845, Australia.

E-mail address: angela.dieterich@postgrad.curtin.edu.au

Telephone: +61 89266 4644, fax +61 892663699

The authors report no declarations of interest.

\footnotetext{
${ }^{\text {a }}$ School of Physiotherapy and Exercise Science, Curtin Health Innovation Research Institute (CHIRI), Curtin University, Perth, Australia,

${ }^{b}$ Department of Imaging and Applied Physics, Curtin University, Perth, Australia
} 
Ultrasound imaging of hip abductors

\section{ABSTRACT}

The hip abductors gluteus medius (Gmed) and minimus (Gmin) differ slightly in function and how they are affected by hip joint pathology. A separate assessment of Gmed and Gmin is feasible by ultrasound (US) imaging. B-mode and M-mode US

5 can be used to measure muscle thickness. Two B- and two M-mode scans of Gmed and Gmin thickness were taken in relaxation on sixteen asymptomatic volunteers, repeated within four days on eleven subjects. Three types of intra-rater reliability of muscle thickness measurements were examined: within-session reliability comparing two scans from the same session, between-days reliability comparing thickness from

10 two scanning occasion within four days, and reliability of taking thickness measurements by re-measuring the same US scans after one week. Thickness measurements on $\mathrm{B}$ - and $\mathrm{M}$-mode images provided $\mathrm{ICC}_{3,1}>0.96$ for within-session reliability. $I C C_{3, k}>0.89$ for between-days reliability and $I C C_{3,1}>0.85$ for re-reading the same scans were estimated. Minimal detectable changes $>1.0 \mathrm{~mm}$ within-session, $>2.4 \mathrm{~mm}$ between-days and $>1.7 \mathrm{~mm}$ for re-reading scans indicated that small thickness changes are not detectable. The investigation suggests a slight advantage for fascia recognition in B-mode and the advantage of visual control of muscle relaxation in M-mode. 
Ultrasound imaging of hip abductors

\section{INTRODUCTION}

The hip abductors play a central role in controlling lateral stability not only for the hip joint but also for the knee joint (Boling, Padua and Creighton 2009) and the lower spine (Nelson-Wong, Gregory, Winter and Callaghan 2008). Recent literature

5 suggests differentiating the activity of superficial and deep hip abductors, as the muscles may be individually affected by pathology (Sims, Richardson and Brauer 2002; Grimaldi, Richardson, Stanton, Durbridge et al 2009).

Gluteus medius (Gmed) and gluteus minimus (Gmin) differ with regard to moment 10 arms, muscle architecture and muscle composition, an indication for functional differences between the two main hip abductors. Modelled moment arms of the anterior, middle and posterior Gmed and Gmin indicate that Gmed is the stronger abductor (Pressel and Lengsfeld 1998; Neumann 2010) and more effective as an external rotator (Delp, Hess, Hungerford and Jones 1999; Neumann 2010). Gmin's anterior part acts as a hip flexor, a function not shared by the anterior Gmed (Neumann 2010). Gmed primarily controls hip abduction range of motion, which is indicated by the longer fibre length, $7.3( \pm 1.6) \mathrm{cm}$ (Ward, Eng, Smallwood and Lieber 2009) versus $4 \mathrm{~cm}$ in Gmin (Beck, Sledge, Gautier, Dora et al 2000). Gmin has primarily stabilizing abilities. The moment arms of external/internal rotation of Gmin 20 change less with hip flexion (Delp, Hess, Hungerford and Jones 1999), allowing for stabilization of femoral rotation during sagittal plane motion. Gmin composition includes more than twice as many muscle spindles than Gmed (Stillman 2000) and a high content of slow twitch fibres (Hitomi, Kizaki, Watanabe, Matsumura et al 2005). Evidence of a differential activity of Gmed and Gmin was documented in a magnetic 25 resonance imaging (MRI) study on asymptomatic subjects (Kumagai, Shiba, Higuchi, Nishimura et al 1997). In subjects with early hip osteoarthritis, electromyography (EMG) and MRI studies indicated increased activity of Gmed, which was thought to compensate for deficits in Gmin (Sims, Richardson and Brauer 2002; Grimaldi, Richardson, Stanton, Durbridge et al 2009). Structural and functional differences between Gmed and Gmin require a separate assessment.

[insert figure 1]

A non-invasive, clinically relevant method for assessing superficial Gmed and also the deep Gmin muscle is ultrasound (US) imaging (Ikezoe, Mori, Nakamura and 
Ichihashi 2011). In a rehabilitative context, measurements of muscle thickness or of the change of thickness during activity are most commonly reported. One important condition of reliable thickness measurements is a consistent scanning angle (Klimstra, Dowling, Durkin and MacDonald 2007; Whittaker, Warner and Stokes

5 2009). As the iliac bone and muscle fasciae are not parallel with the skin surface, the transducer handle must tilted towards the subjects back to direct the US-beam perpendicular onto the iliac bone. The angle of tilt of the transducer needs to be reproduced to achieve reliable thickness measurements of Gmed and Gmin. Of particular importance are reliable baseline measurements of muscle thickness in relaxation that enable the detection of thickness change during muscle activity.

Muscle thickness can be measured by Brightness (B)-mode US or by Motion (M)mode US. B-mode US provides a two-dimensional image of the scanned tissue section (Figure 1a), in which the sound reflecting interfaces of muscle fasciae and

15 perimysium are delineated as bright structures (Walker, Cartwright, Wiesler and Caress 2004). A B-mode image facilitates anatomic recognition, but the measurement location and angle have to be set manually, which may introduce error. Muscle relaxation may be difficult to judge in a B-mode US image, and needs to be assessed by palpation or additional EMG. M-mode US provides a trace of the

20 displacement of fasciae and perimysium over time (figure 2): the position of interfaces in a single sound-beam is plotted every few milliseconds ( $\mathrm{ms}$ ) creating a trace of tissue movement. In M-mode, the measurement location and angle is fixed which may improve measurement repeatability. M-mode enables the monitoring of muscle motion with high temporal resolution and also the measurement of activation onset (Vasseljen, Dahl, Mork and Torp 2006). In a comparison of abdominal muscle thickness measurements by B-mode and M-mode US, both modes produced reliable thickness measurements (McMeeken, Beith, Newham, Milligan et al 2004). In both modes, US scans provide often slightly blurred contours of muscle fasciae which complicates a reliable determination of the inner edges of the fasciae from which muscle thickness should be measured (Whittaker 2007, p.99).

\section{[insert figure 2]}

This study aimed to compare B-mode and M-mode baseline measurements of relaxed Gmed and Gmin thickness by three aspects of intra-tester reliability, 
Ultrasound imaging of hip abductors

repeated scans within-session, repeated scans between-days and repeated measurements on the same scans after one week. A further objective was to document the scanning procedure and muscle identification.

\section{METHODS}

Gmed and Gmin thickness was measured in the intervals between maximal voluntary isometric contractions (MVIC) using B-mode and M-mode US in two US scanning sessions (day 1 and day 2) within one week. Measurements in between phases of maximal activity were taken to examine the repeatability of the baseline measurements. Surface EMG was used to control for Gmed relaxation.

\section{Subjects}

Subjects without hip pain, history of hip pathology or general musculoskeletal disease were included if they had a $\mathrm{BMI}<32 \mathrm{~kg} / \mathrm{m}^{2}$, as adipose tissue compromises US imaging. Approval for the study was obtained from the University's Human

15 Research Ethics Committee. Subjects provided informed consent.

\section{Instrumentation}

US: Antares 4.0 system (Siemens Medical Solutions, USA), 4-9 Hz linear probe (VFX9-4) set to $9 \mathrm{Mhz}, 38 \mathrm{~mm}$ footprint. A custom application was programmed to delineate high contrast for distinguishing bright (hyperechoic) collagenous interfaces

20 against dark (hypoechoic) contractile tissue. The M-mode settings included a small B-mode image for anatomic orientation on top of the M-mode trace which displayed $1.4 \mathrm{~s}$ at highest sweep speed. Surface EMG: Octopus AMT-8EMG system, Bortec Electronics Inc., Calgary, Canada, synchronized to the US unit by an Event Synchronization Unit (PEAK Performance Technologies Inc., Centennial, CO, USA).

\section{Procedure}

Scanning of the right hip abductors was performed in supine in a neutral hip position. The transducer was housed in a foam block, excavated at a $20^{\circ}$ angle, which was fixed to the pelvis by elastic belts (Bunce, Hough and Moore 2004; Mannion, Pulkovski, Schenk, Hodges et al 2008). The scanning location was determined on the lower half of a line which connected the ventral quarter of the distance between the right ASIS and PSIS with the tip of the greater trochanter (figure 3). The US system was set with the necessary power to show a clear delineation of the iliac periosteum, with the right side of the image towards the greater trochanter. A single 
focal zone was set to the Gmin aponeurosis. Following skin preparation, two surface electrodes were attached on the reference line cranial to the foam block on the same Gmed section as measured by US and two electrodes were attached behind the foam block on the recommended EMG position (Merletti, Farina, Hermens, Freriks et

5 al 1999), both with an interelectrode distance of $22 \mathrm{~mm}$ (figure 3). A ground electrode was attached on the lateral ribs. The following sequence of events was recorded with relaxation phases of approximately $40 \mathrm{~s}$ length: in B-mode relaxationMVIC-relaxation-MVIC, then in M-mode relaxation-MVIC-relaxation. [insert figure 3]

\section{Muscle identification}

The iliac periosteum forms the deep border of Gmin, the deepest interface in the image (figure 1). The Gmin aponeurosis is visible as a hyperechoic band setting a continuous demarcation towards Gmed. Above the aponeurosis lies the thick bulk of Gmed which is divided by a hyperechoic, thin, not necessarily continuous structure.

15 The superficial fascia of Gmed is easily identified in dynamic imaging, whereas in static images it blends into the fascia lata. Following the periosteum towards the hip joint, a hyperechoic structure between Gmin and the iliac periosteum can be identified. This structure likely represents the reflected head of the rectus femoris muscle (Nan̆ka, Havránek, Pešl and Dutka 2003). It is hardly identifiable on the midsagittal view (Figure 1), but becomes more evident towards the ventral scanning location used in this study (Figure 2). To differentiate the tensor fasciae latae (TFL) muscle the transducer was turned $90^{\circ}$ to transverse scanning. In the anterior part of the iliac bone TFL is identified as a triangular shape, superficial to Gmed.

\section{US measurements}

25 US recordings were captured at 25 frames per second onto standard definition video (Panasonic digital video camera, NV-MX500A, Secaucus, USA) and digitized (iMovie 5.0.2). On the computer two B-mode and two M-mode images were cut from the relaxation phases indicated by lowest EMG amplitude and non-moving muscle fasciae. Gmed and Gmin thickness was measured on enlarged (150\%) images using

30 ImageJ software (version 1.40; rsb.info.nih.gov/ij/). The examiner was blinded to measurements from the other mode or occasion. The measurement position was determined at the cranial edge of the reflected head of rectus femoris. Thickness was measured from the inner edges of the fasciae (Whittaker 2007, p.99). 
B-mode measurements were taken perpendicular to the longitudinal axis of the muscle bulk. In M-mode the sound-beam, thus the line along which thickness is measured, is perpendicular to the footprint of the US transducer; the angle of the sound-beam towards the muscle may differ from the measurement line in B-mode.

5 Angle variation of the M-mode sound-beam towards the aponeurosis and the periosteum was documented (figure 2).

For estimating within-session reliability, all scans taken first were compared to the second scans from day 1. For assessing between-days reliability, scans of day 1 and day 2 were compared. For examining the reliability of taking the measurement, all scans of day 1 were measured a second time after one week.

\section{Statistics}

Gmed and Gmin thickness were described by mean and standard deviation (SD). Differences between B-mode and M-mode measurements of muscle thickness were examined by paired $t$-test. Angle variation of the M-mode sound-beam was

15 documented by mean SD.

Within-session, between-days and within-image (Costa, Maher, Latimer and Smeets 2009) reliability of relaxed muscle thickness were estimated by intra-class correlation coefficients $\mathrm{ICC}_{3,1}$ for single and $\mathrm{ICC}_{3, k}$ for averaged measures and by mean difference, SD, typical error (SEM) (Hopkins 2000) and minimal detectable change (MDC). The MDC is a statistical measure that indicates which change of a measurement can be considered with 95\% certainty to be a 'true' change (Donoghue, Physiotherapy Research and Older People group and Stokes 2009). Significance was set to $\alpha=0.05$. If not specified otherwise results are reported as mean SD.

\section{RESULTS}

Sixteen volunteers, ten females aged 30.1 SD 10.6 years with BMI of 22.6 SD 4.2 $\mathrm{kg} / \mathrm{m}^{2}$ and six males aged 28.8 SD 6.2 years with BMI of $22.2 \mathrm{SD} 2.6 \mathrm{~kg} / \mathrm{m}^{2}$ participated on day 1 . Eleven volunteers, six females and five males, participated 30 also on day 2. In each mode, 54 US images of the hip abductors were included in the study. 
B-mode and M-mode thickness measurements (tables 1 and 2) did not differ significantly $(p=0.2-0.8)$. The angle of the M-mode sound-beam towards the aponeurosis was $82.3^{\circ} \mathrm{SD} 8.8^{\circ}$, and towards the periosteum $90.0^{\circ} \mathrm{SD} 10.0^{\circ}$. Excellent within-session reliability of measurements of abductor muscle thickness

5 (table 1) was found. Between-days reliability (table 2) and reliability of re-reading scans after one week (table 3) was good (Portney and Watkins 2000). The MDC for within-session measurements was estimated 5-7\% of Gmed and 6-8\% of Gmin thickness. The MDC for measurements between days ranged from $10-13 \%$ of Gmed and $15-17 \%$ of Gmin thickness.

10 [insert tables 1,2 and 3]

An additional observation related to the assessment of muscle relaxation. M-mode US indicated muscle relaxation by the absence of motion (figure 2), visible as straight, horizontal traces of the interfaces. M-mode US revealed isolated Gmin motion while Gmed stayed relaxed (figure 4).

15 [insert figure 4]

\section{DISCUSSION}

Hip abductor thickness can be measured by B-mode or M-mode US; in both modes good to excellent measurement reliability was demonstrated. The variation of

20 baseline measurements of relaxed muscle thickness was slightly less in B-mode, resulting in a 0.4-6.4\% higher sensitivity to detect activity. Are the scanned muscles relaxed in baseline measurements? M-mode revealed occasional isolated Gmin motion not shared by Gmed. This observation suggests that Gmin may be active in isolation and that a visual assessment of relaxation in the deep Gmin muscle by $\mathrm{M}$ -

25 mode US may be valuable.

The relative reliability documented in this study indicated ICCs reliability within the range reported in the literature on trunk muscles (Costa, Maher, Latimer and Smeets 2009; Hebert, Koppenhaver, Parent and Fritz 2009; Koppenhaver, Hebert, Fritz,

Parent et al 2009). The absolute measurement error of within-session reliability, expressed by the SEM, was comparable to measurements on the abdominals by Mannion et al (2008) and by Critchley and Coutts (2002) but higher than reported by Teyhen et al (2005). Absolute error of between-days reliability was comparable to 
the results of Kidd et al (2002) and slightly higher than those by Hides et al (2007). Reliability of re-measuring the same scans was lower than reported in the literature (Teyhen, Miltenberger, Deiters, Del Toro et al 2005; Hides, Miokovic, Belav, Stanton et al 2007), however in these reports scans were re-measured on the same day. The lower reliability of re-measuring scans after a week likely indicates inconsistencies in the recognition of the inner edges of muscle fasciae.

Considering the larger depth of the hip abductors, the inclusion of overweight subjects and the oblique scanning approach, a reasonable measurement quality is documented. Marginally lower ICCs for M-mode compared to B-mode measurements were indicated in concordance with McMeeken et al (2004). The percentage of MDC was higher in the thinner Gmin, a finding which demonstrates the principal difficulty to detect small thickness changes in thin muscles (Koppenhaver, Hebert, Fritz, Parent et al 2009; Teyhen, George, Dugan, Williamson et al 2011). The precision of US measures of muscle thickness is not

15 good enough to detect small thickness changes. Comparing B- and M-mode US, three points of importance for the precision of muscle thickness measurements are discussed in the following.

\section{Recognition of muscle fasciae}

20 The B-mode image is a reflection of a tissue cross section, compromised by speckle and reflective phenomena. The two-dimensional B-mode image facilitates the recognition of anatomic structures based on their spatial arrangement, their shape, their continuity and brightness. In the M-mode trace, every reflective interface in the sound-beam produces a continuous line, not only of fascia but also of fascicles

25 (figures 2 and 4). In M-mode, the thickness, the brightness and the sequence of lines are the characteristics for anatomical identification. These characteristics can be deceptive due to the anisotrophic nature of muscle tissue. Anisotrophy is a phenomenon in US imaging which comprises marked changes in brightness by small changes of the scanning angle (Van Holsbeeck and Introcaso 2001, pp.17/18) and it

30 affects the recognition of the edge of muscle fasciae. The effect of anisotrophy on measurements may be larger in M-mode because anatomic recognition relies more strongly on the brightness of lines. Recognition of muscle borders in M-mode needs 
Ultrasound imaging of hip abductors

to be facilitated by an accompanying B-mode image. Also, grouping images of the same subject helps identification.

\section{The angle of thickness measurements}

5 Measurements of muscle thickness should be taken perpendicular to the fasciae (Teyhen, Gill, Whittaker, Henry et al 2007). The manual setting of the B-mode measurements enables perpendicular thickness measurements regardless of the muscles' orientation in the image. In M-mode, the sound-beam, along which thickness is measured, is aligned with the transducer. M-mode thickness

10 measurements perpendicular to the muscle fasciae require a horizontal arrangement of the muscles in the US image, which may be difficult to achieve. In this study, angle variation of the M-mode sound-beam was a source of measurement variation. The documented deviations were within $10^{\circ}$ and should not affect thickness measurements significantly (Klimstra, Dowling, Durkin and MacDonald 2007;

15 Whittaker, Warner and Stokes 2009). Nevertheless, measurement variation reduced the precision of M-mode thickness measurements. This disadvantage of M-mode for thickness measurements may be reduced by a beam-steering option, as utilised in Doppler US and available in some US systems.

\section{Observation of muscle motion and control of relaxation}

According to Hodges et al (2003), most thickening of muscle during activity occurs in low activity levels. The control of muscle relaxation is crucial for establishing the baseline value of relaxed muscle thickness. Muscle activation is accompanied by the motion of muscle tissue (Vasseljen, Dahl, Mork and Torp 2006; Mannion, Pulkovski,

25 Schenk, Hodges et al 2008; Vasseljen, Fladmark, Westad and Torp 2009). These studies indicated that not all muscle motion indicates muscle activity, but provided no evidence for muscle activity without accompanying motion. M-mode is highly sensitive to motion (figure 2, pulsation of a vessel). Isolated Gmin motion was observed (figure 4), which may be an indication of selective, low level activity which

30 cannot be assessed by surface EMG and which is difficult to observe in B-mode. Although not confirmed by fine-wire EMG in this study, it can be assumed that stable, horizontal traces of muscle tissue in the M-mode images indicate muscle relaxation. The straightforward visual recognition of relaxation in deep muscles may 
Ultrasound imaging of hip abductors

be a unique advantage of M-mode US compared to B-mode and to surface EMG (table 4).

[insert table 4]

\section{Study limitations}

5 The focus of this study is basic since it did not include thickness measurements of activity. Valid baseline measurements are the precondition of the assessment of thickness change by activity. The main characteristics of B-mode and M-mode US thickness measurements are reflected in this study. No comparable comparison between B- and M-mode US has been reported.

10 From a clinical perspective, a reliability study in which the US transducer is fixed by a device may be questioned. Experienced professionals who trained maintaining the scanning angle while interacting with the subject may not need transducer fixation. To date, US imaging skills are not the focus of physiotherapy training and rather a supplementary assessment. Less experienced users may need pre-prepared

15 equipment for transducer fixation, a limitation to the clinical applicability of repeated hip abductor thickness measurements. A fixation device is recommended to control the scanning angle and transducer pressure in repeated measurements. The scanning angle and its precise reproduction are critical for thickness measurements (Whittaker et al., 2009, Klimstra et al., 2007). The oblique scanning angle required

20 for Gmed and Gmin is difficult to reproduce, even more in a setup that includes activity. Pressure of the transducer needs control because it may affect muscle thickness, in particular in subjects with a thin layer of adipose tissue. The foam block distributes a uniform pressure over a large surface. The foam block, not the transducer was fixed to the pelvis, so that no specific pressure was exerted on the

25 transducer.

As documented in Figures 1,2 and 4, the image quality provided by video recording is limited. A digital recording technique would have enhanced image quality. From a statistical point of view, the sample sizes of sixteen for within-session and of eleven for between-days reliability may be judged insufficient (Walter et al 1998),

30 although reliability studies with comparable sample sizes are well-accepted in the medical imaging field (Alshami, Cairns, Wylie, Souvlis et al 2009; Dudley-Javoroski, McMullen, Borgwardt, Peranich et al 2010; E Lima, Da Matta and de Oliveira 2012). 
Ultrasound imaging of hip abductors

An important limitation of this study was that gluteus minimus relaxation was not controlled by fine-wire EMG. Ethically, for the control of relaxation alone, the invasive procedure could not be justified.

\section{Implications for physiotherapy practice}

5 Within-session reliability of B-mode and M-mode thickness measurements of Gmed and Gmin was high, with a slight preference for the use of B-mode. Between-days reliability was good and did not differ between B-mode and M-mode US. M-mode US may enable the assessment of relaxation in deep muscles, an advantage for establishing 'true' baseline measurements of muscle thickness. 


\section{REFERENCES}

Alshami A, C Cairns, B Wylie, T Souvlis and M Coppieters 2009 Reliability and size of the measurement error when determining the cross-sectional area of the tibial nerve at the tarsal tunnel with

5 ultrasonography. Ultrasound in Medicine \& Biology 35: 1098-1102.

Beck M, JB Sledge, E Gautier, CF Dora and R Ganz 2000 The anatomy and function of the gluteus minimus muscle. Journal of Bone \& Joint Surgery - British Volume 82: 358-363.

Boling M, D Padua and RA Creighton 2009 Concentric and eccentric torque of the hip musculature in individuals with and without patellofemoral pain. Journal of Athletic Training 44: 7-13.

10 Bunce SM, AD Hough and AP Moore 2004 Measurement of abdominal muscle thickness using M-mode ultrasound imaging during functional activities. Manual Therapy41-44.

Costa LOP, C Maher, J Latimer and RJEM Smeets 2009 Reproducibility of rehabilitative ultrasound imaging for the measurement of abdominal muscle activity: a systematic review. Physical Therapy 89 : 756-769.

15 Critchley DJ and FJ Coutts 2002 Abdominal Muscle Function in Chronic Low Back Pain Patients: Measurement with real-time ultrasound scanning. Physiotherapy 88: 322-332.

Delp SL, WE Hess, DS Hungerford and LC Jones 1999 Variation of rotation moment arms with hip flexion. Journal of Biomechanics 32: 493-501.

Donoghue D, P Physiotherapy Research and Older People group and EK Stokes 2009 How much change is

20 true change? The minimum detectable change of the Berg Balance Scale in elderly people. Journal of Rehabilitation Medicine 41: 343-346.

Dudley-Javoroski S, T McMullen, MR Borgwardt, LM Peranich and RK Shields 2010 Reliability and Responsiveness of Musculoskeletal Ultrasound in Subjects with and without Spinal Cord Injury. Ultrasound in Medicine \& Biology 36: 1594-1607. 


\section{Ultrasound imaging of hip abductors}

E Lima KMM, TT Da Matta and LF de Oliveira 2012 Reliability of the rectus femoris muscle cross-sectional area measurements by ultrasonography. Clinical Physiology and Functional Imaging 32: 221-226.

Grimaldi A, CA Richardson, W Stanton, G Durbridge, W Donnelly and J Hides 2009 The association between degenerative hip joint pathology and size of the gluteus medius, gluteus minimus and piriformis muscles. Manual Therapy 14: 605-610.

Hebert J, S Koppenhaver, E Parent and J Fritz 2009 A systematic review of the reliability of rehabilitative ultrasound imaging for the quantitative assessment of the abdominal and lumbar trunk muscles. Spine 34: E848-E856.

Hides J, T Miokovic, D Belav, W Stanton and CA Richardson 2007 Ultrasound imaging assessment of

10 abdominal muscle function during drawing-in of the abdominal wall: an intrarater reliability study. Journal of Orthopaedic and Sports Physical Therapy 37: 480-486.

Hitomi Y, T Kizaki, S Watanabe, G Matsumura, Y Fujioka, S Haga, T Izawa, N Taniguchi and H Ohno 2005 Seven skeletal muscles rich in slow muscle fibers may function to sustain neutral position in the rodent hindlimb. Comparative Biochemistry and Physiology - Part B: Biochemistry and Molecular Biology 140: 45-50.

Hodges P, LHM Pengel, RD Herbert and SC Gandevia 2003 Measurement of muscle contraction with ultrasound imaging. Muscle \& Nerve 27: 682-692.

Hopkins WG 2000 Measures of reliability in sports medicine and science. Sports Medicine 30: 1-15.

Ikezoe T, N Mori, M Nakamura and N Ichihashi 2011 Atrophy of the lower limbs in elderly women: is it related to walking ability? European Journal of Applied Physiology 111: 989-995.

Klimstra M, J Dowling, JL Durkin and M MacDonald 2007 The effect of ultrasound probe orientation on muscle architecture measurement. Journal of Electromyography and Kinesiology 17: 504-514.

Koppenhaver S, J Hebert, J Fritz, E Parent, D Teyhen and J Magel 2009 Reliability of rehabilitative ultrasound imaging of the transversus abdominis and lumbar multifidus muscles. Archives of Physical 25 Medicine and Rehabilitation 90: 87-94. 


\section{Ultrasound imaging of hip abductors}

Kumagai M, N Shiba, F Higuchi, H Nishimura and A Inoue 1997 Functional evaluation of hip abductor muscles with use of Magnetic Resonance Imaging. Journal of Orthopaedic Research 15: 888-893.

Mannion A, N Pulkovski, P Schenk, PW Hodges, H Gerber, T Loupas, M Gorelick and H Sprott 2008 A new method for the noninvasive determination of abdominal muscle feedforward activity based on tissue

5 velocity information from tissue Doppler imaging. Journal of Applied Physiology 104: 1192-1201.

Mannion AF, N Pulkovski, D Gubler, M Gorelick, D O'Riordan, T Loupas, P Schenk, H Gerber and H Sprott 2008 Muscle thickness changes during abdominal hollowing: an assessment of between-day measurement error in controls and patients with low back pain. European Spine Journal 17: 494-501.

McMeeken JM, ID Beith, DJ Newham, P Milligan and DJ Critchley 2004 The relationship between EMG and 10 change in thickness of transversus abdominis. Clinical Biomechanics 19: 337-342.

Merletti R, D Farina, H Hermens, B Freriks and J Harlaar 1999 SENIAM - European Recommendations for Surface Electromyography. SENIAM - European Recommendations for Surface Electromyography. Hermens HJ, Freriks B, Merletti R, Stegemann D, Blok J, Rau G, Disselhorst-Klug C and Haegg G, Roessingh Research and Development.

15 Nan̆ka O, P Havránek, T Pešl and J Dutka 2003 Avulsion fracture of the pelvis: Separation of the secondary ossification center in the superior margin of the acetabulum. Clinical Anatomy 16: 458-460.

Nelson-Wong E, DE Gregory, DA Winter and JP Callaghan 2008 Gluteus medius muscle activation patterns as a predictor of low back pain during standing. Clinical Biomechanics 23: 545-553.

Neumann DA 2010 Kinesiology of the hip: a focus on muscular actions. Journal of Orthopaedic and Sports Physical Therapy 40: 82-94.

Portney LG and MP Watkins 2000 Foundations of clinical research. Upper Saddle River, New Jersey 07458, Prentice-Hall Health.

Pressel T and M Lengsfeld 1998 Functions of hip joint muscles. Medical Engineering \& Physics 20: 50-56.

Sims KJ, CA Richardson and SG Brauer 2002 Investigation of hip abductor activation in subjects with 25 clinical unilateral hip osteoarthritis. Annals of the Rheumatic Diseases 61: 687-692. 


\section{Ultrasound imaging of hip abductors}

Stillman BC 2000 An investigation of the clinical assessment of joint position sense. PhD Thesis. School of Physiotherapy. Melbourne, University of Melbourne. PhD.

Teyhen D, S George, J Dugan, J Williamson, B Neilson and J Childs 2011 Inter-rater reliability of ultrasound imaging of the trunk musculature among novice raters. Journal of Ultrasound in Medicine 30: 347-356.

5 Teyhen D, C Miltenberger, H Deiters, Y Del Toro, J Pulliam, J Childs, R Boyles and T Flynn 2005 The use of ultrasound imaging of the abdominal drawing-in maneuver in subjects with low back pain. Journal of Orthopaedic and Sports Physical Therapy 35: 346-355.

Teyhen DS, N Gill, J Whittaker, S Henry, J Hides and PW Hodges 2007 Rehabilitative ultrasound imaging of the abdominal muscles. Journal of Orthopaedic and Sports Physical Therapy 37: 450-466.

10 Van Holsbeeck MT and JH Introcaso 2001 Musculoskeletal Ultrasound. St. Louis, Mosby.

Vasseljen O, HH Dahl, PJ Mork and HG Torp 2006 Muscle activity onset in the lumbar multifidus muscle recorded simultaneously by ultrasound imaging and intramuscular electromyography. Clinical Biomechanics 21: 905-913.

Vasseljen 0, AM Fladmark, C Westad and HG Torp 2009 Onset in abdominal muscles recorded

15 simultaneously by ultrasound imaging and intramuscular electromyography. Journal of Electromyography and Kinesiology 19: e23-31.

Walker FO, MS Cartwright, ER Wiesler and J Caress 2004 Ultrasound of nerve and muscle. Clinical Neurophysiology 115: 495-507.

Ward SR, CM Eng, LH Smallwood and RL Lieber 2009 Are current measurements of lower extremity architecture accurate? Clinical Orthopaedics and Related Research 467: 1074-1082.

Whittaker JL 2007 Ultrasound imaging for rehabilitation of the lumbopelvic region Philadelphia, Elsevier Churchill Livingstone.

Whittaker JL, MB Warner and MJ Stokes 2009 Induced transducer orientation during ultrasound imaging: effects on abdominal muscle thickness and bladder position. Ultrasound in Medicine \& Biology 35: 18031811. 
Ultrasound imaging of hip abductors

\section{TABLES}

Table 1. Within-session reliability of relaxed gluteus medius and minimus thickness measurements in B- and Mmode ultrasound, intraclass correlation coefficients (ICC), confidence intervals (CI), standard error of measurement $(\mathrm{SEM})$ and minimal detectable change (MDC, $=\mathrm{SEM} \times \sqrt{ } 2 \times 1.96)$.

\begin{tabular}{lcccc}
\hline \multicolumn{1}{c}{$\mathbf{n}=\mathbf{1 6}$} & $\begin{array}{c}\text { B-mode gluteus } \\
\text { medius }\end{array}$ & $\begin{array}{c}\text { B-mode gluteus } \\
\text { minimus }\end{array}$ & $\begin{array}{c}\text { M-mode gluteus } \\
\text { medius }\end{array}$ & $\begin{array}{c}\text { M-mode gluteus } \\
\text { minimus }\end{array}$ \\
\hline Thickness day 1, & $23.2(2.5)$ & $16.6(2.1)$ & $23.4(3.0)$ & $17.0(2.6)$ \\
mean $(\mathrm{SD}), \mathrm{mm}$ & 0.973 & 0.957 & 0.959 & 0.980 \\
\hline $\mathrm{ICC}_{3,1}(\mathrm{Cl})$ & $(0.924-0.990)$ & $(0.881-0.985)$ & $(0.888-0.986)$ & $(0.944-0.993)$ \\
& $0.1 \pm 0.6$ & $0.1 \pm 0.6$ & $0.2 \pm 0.9$ & $0.2 \pm 0.5$ \\
Difference $\pm \mathrm{SD}, \mathrm{mm}$ & 0.4 & 0.4 & 0.6 & 0.4 \\
SEM, mm & 1.2 & 1.3 & 1.7 & 1.0 \\
MDC, mm & $5.0 \%$ & $7.5 \%$ & $7.2 \%$ & $6.1 \%$ \\
MDC \% of thickness & & & &
\end{tabular}

Table 2. Between-days reliability of relaxed gluteus medius and minimus thickness measurements in B-and $\mathrm{M}$ mode ultrasound, intraclass correlation coefficients (ICC), confidence intervals (CI), standard error of measurement (SEM) and minimal detectable change (MDC).

\begin{tabular}{|c|c|c|c|c|}
\hline$n=11$ & $\begin{array}{c}\text { B-mode gluteus } \\
\text { medius }\end{array}$ & $\begin{array}{c}\text { B-mode gluteus } \\
\text { minimus }\end{array}$ & $\begin{array}{c}\text { M-mode gluteus } \\
\text { medius }\end{array}$ & $\begin{array}{l}\text { M-mode gluteus } \\
\text { minimus }\end{array}$ \\
\hline Thickness day 1 , & $23.5(2.8)$ & $16.7(2.1)$ & $23.7(3.5)$ & $17.1(2.6)$ \\
\hline $\begin{array}{l}\text { Thickness day 2, } \\
\text { mean (SD), mm }\end{array}$ & $22.9(2.9)$ & $16.5(2.4)$ & $23.4(2.7)$ & $17.7(2.4)$ \\
\hline $\begin{array}{l}\text { Single measures, } \\
\mathrm{ICC}_{3,1}(\mathrm{Cl})\end{array}$ & $\begin{array}{c}0.884 \\
(0.742-0.950)\end{array}$ & $\begin{array}{c}0.788 \\
(0.556-0.906)\end{array}$ & $\begin{array}{c}0.869 \\
(0.711-0.943)\end{array}$ & $\begin{array}{c}0.803 \\
(0.584-0.913)\end{array}$ \\
\hline Difference $\pm S D, m m$ & $0.3 \pm 1.6$ & $0.5 \pm 1.6$ & $-0.3 \pm 1.6$ & $0.6 \pm 1.6$ \\
\hline $\mathrm{SEM}, \mathrm{mm}$ & 1.1 & 1.1 & 1.1 & 1.1 \\
\hline $\mathrm{MDC}, \mathrm{mm}$ & 2.5 & 2.6 & 3.1 & 3.0 \\
\hline MDC \% of thickness & $10.7 \%$ & $15.4 \%$ & $13.1 \%$ & $17.5 \%$ \\
\hline $\begin{array}{l}\text { Average of } 2 \text { scans, } \\
\text { ICC }_{3, k}(\mathrm{Cl})\end{array}$ & $\begin{array}{c}0.948 \\
(0.808-0.986)\end{array}$ & $\begin{array}{c}0.888 \\
(0.584-0.970)\end{array}$ & $\begin{array}{c}0.938 \\
(0.626-0.967)\end{array}$ & $\begin{array}{c}0.897 \\
(0.618-0.972)\end{array}$ \\
\hline Difference $\pm S D, m m$ & $0.3 \pm 1.5$ & $0.5 \pm 1.6$ & $-0.3 \pm 1.5$ & $0.6 \pm 1.5$ \\
\hline SEM, mm & 1.0 & 1.1 & 1.1 & 1.1 \\
\hline $\mathrm{MDC}, \mathrm{mm}$ & 2.4 & 2.5 & 3.0 & 3.0 \\
\hline MDC $\%$ of thickness & $10.4 \%$ & $14.9 \%$ & $12.6 \%$ & $17.3 \%$ \\
\hline
\end{tabular}


Table 3. Reliability re-measuring the two scans of day 1 after one week, intraclass correlation coefficients (ICC), confidence intervals $(\mathrm{Cl})$, standard error of measurement (SEM) and minimal detectable change (MDC).

\begin{tabular}{lcccc}
\hline \multicolumn{1}{c}{$\mathbf{n = 1 6}$} & $\begin{array}{c}\text { B-mode gluteus } \\
\text { medius }\end{array}$ & $\begin{array}{c}\text { B-mode gluteus } \\
\text { minimus }\end{array}$ & $\begin{array}{c}\text { M-mode } \\
\text { gluteus medius }\end{array}$ & $\begin{array}{c}\text { M-mode gluteus } \\
\text { minimus }\end{array}$ \\
\hline ICC $_{3,1}(\mathrm{Cl})$ & 0.869 & 0.865 & 0.852 & 0.865 \\
& $(0.748-0.934)$ & $(0.741-0.932)$ & $(0.718-0.921)$ & $(0.741-0.932)$ \\
Difference $\pm S D, m m$ & $0.0 \pm 0.9$ & $0.2 \pm 0.9$ & $-0.1 \pm 1.1$ & $-0.5 \pm 1.3$ \\
SEM, mm & 0.6 & 0.6 & 0.7 & 1.0 \\
MDC, mm & 1.7 & 1.7 & 2.1 & 2.6 \\
MDC \% of thickness & $7.3 \%$ & $10.6 \%$ & $8.9 \%$ & $15.2 \%$ \\
\hline
\end{tabular}

Table 4. B-mode and M-mode US for measuring muscle thickness.

\begin{tabular}{llllll}
\hline & $\begin{array}{l}\text { Within- } \\
\text { session } \\
\text { reliability }\end{array}$ & $\begin{array}{l}\text { Between- } \\
\text { days } \\
\text { reliability }\end{array}$ & $\begin{array}{l}\text { Muscle border } \\
\text { recognition }\end{array}$ & $\begin{array}{l}\text { Consistency of } \\
\text { measurement } \\
\text { angle }\end{array}$ & $\begin{array}{l}\text { Control of muscle } \\
\text { relaxation }\end{array}$ \\
\hline $\begin{array}{l}\text { B-mode, } \\
\text { SEM mm }\end{array}$ & ICC $>0.97$ & ICC $>0.88$ & $\begin{array}{l}\text { Facilitated by } \\
\text { 2-dimensional } \\
\text { image }\end{array}$ & $\begin{array}{l}\text { Can be } \\
\text { achieved } \\
\text { manually }\end{array}$ & $\begin{array}{l}\text { No image of } \\
\text { motion }\end{array}$ \\
$\begin{array}{llll}\text { M-mode, } \\
\text { SEM mm }\end{array}$ & ICC $>0.6-0.91 .1$ & ICC $>0.89$ & $\begin{array}{l}\text { Needs } \\
\text { comparison to } \\
\text { B-mode }\end{array}$ & $\begin{array}{l}\text { Has to be } \\
\text { achieved } \\
\text { initially in the } \\
\text { set-up }\end{array}$ & $\begin{array}{l}\text { Trace of motion } \\
\text { over time, highly } \\
\text { sensitive to } \\
\text { motion }\end{array}$ \\
\hline
\end{tabular}




\section{CAPTIONS OF FIGURES AND TABLES}

Figure 1. Longitudinal B-mode US view on the gluteus medius and minimus muscles manually collated for anatomical orientation. The grey frame indicates the field of view which was scanned in the study for thickness measurements. Arrowhead points at a structure which presumably is the reflected head of rectus femoris.

Figure 2. M-mode trace of the onset of isometric abductor activity. Muscle relaxation before activity is indicated by undisturbed horizontal lines, pulsation of a vessel is detectible as slight line displacement in gluteus minimus (larger arrowhead). Sustained activity can be distinguished from relaxation by less stable $\mathrm{M}$-mode lines. Arrows point at the angles of the M-mode sound-beam towards the gluteus medius fascia and aponeurosis which were measured to assess angle variation. Smaller arrowhead indicates reflected head of rectus femoris in the B-mode image.

Figure 3. Reference line connecting the tip of the greater trochanter to the anterior quarter of a line between ASIS and PSIS, surface electrode positions. The US transducer was positioned on the lower half of the reference line.

15 Figure 4. Isolated gluteus minimus motion that preceded the activity of gluteus medius by 640 ms.

Table 1. Within-session reliability of relaxed gluteus medius and minimus thickness measurements in B- and Mmode ultrasound, intraclass correlation coefficients (ICC), confidence intervals (CI), standard error of measurement $(\mathrm{SEM})$ and minimal detectable change $(\mathrm{MDC},=\mathrm{SEM} \times \sqrt{2} \times 1.96)$.

20 Table 2. Between-days reliability of relaxed gluteus medius and minimus thickness measurements in B- and Mmode ultrasound, intraclass correlation coefficients (ICC), confidence intervals (CI), standard error of measurement (SEM) and minimal detectable change (MDC).

Table 3. Reliability of re-measuring the two scans of day 1 after one week, intraclass correlation coefficients (ICC), confidence intervals ( $\mathrm{Cl}$ ), standard error of measurement (SEM) and minimal detectable change (MDC).

Table 4. B-mode and M-mode US for measuring muscle thickness. 
Ultrasound imaging of hip abductors
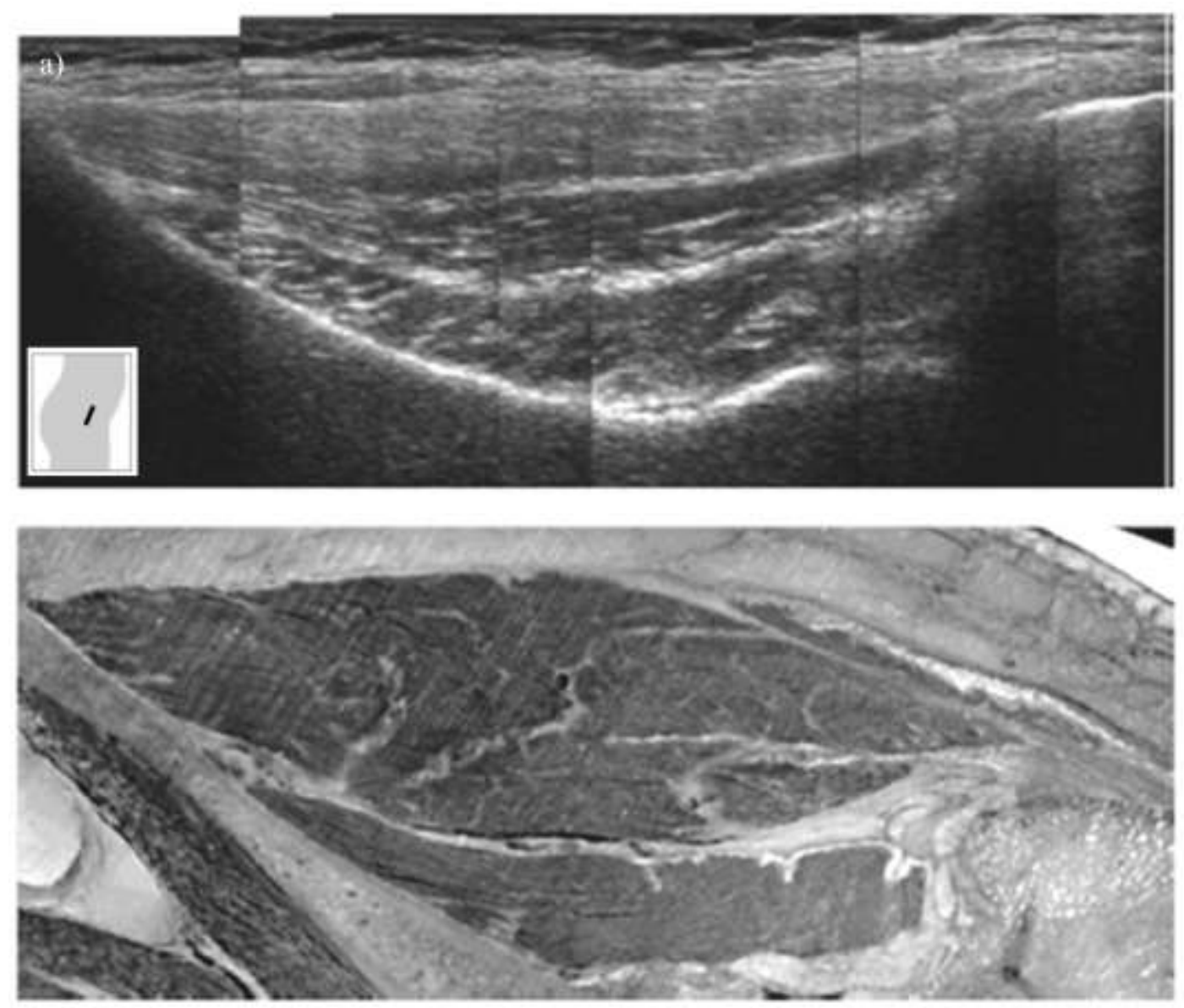

Figure 1. Longitudinal B-mode US view on the gluteus medius and minimus muscles manually collated for anatomical orientation. The grey frame indicates the field of

5 view which was scanned in the study for thickness measurements. Arrowhead points at a structure which presumably is the reflected head of rectus femoris. 


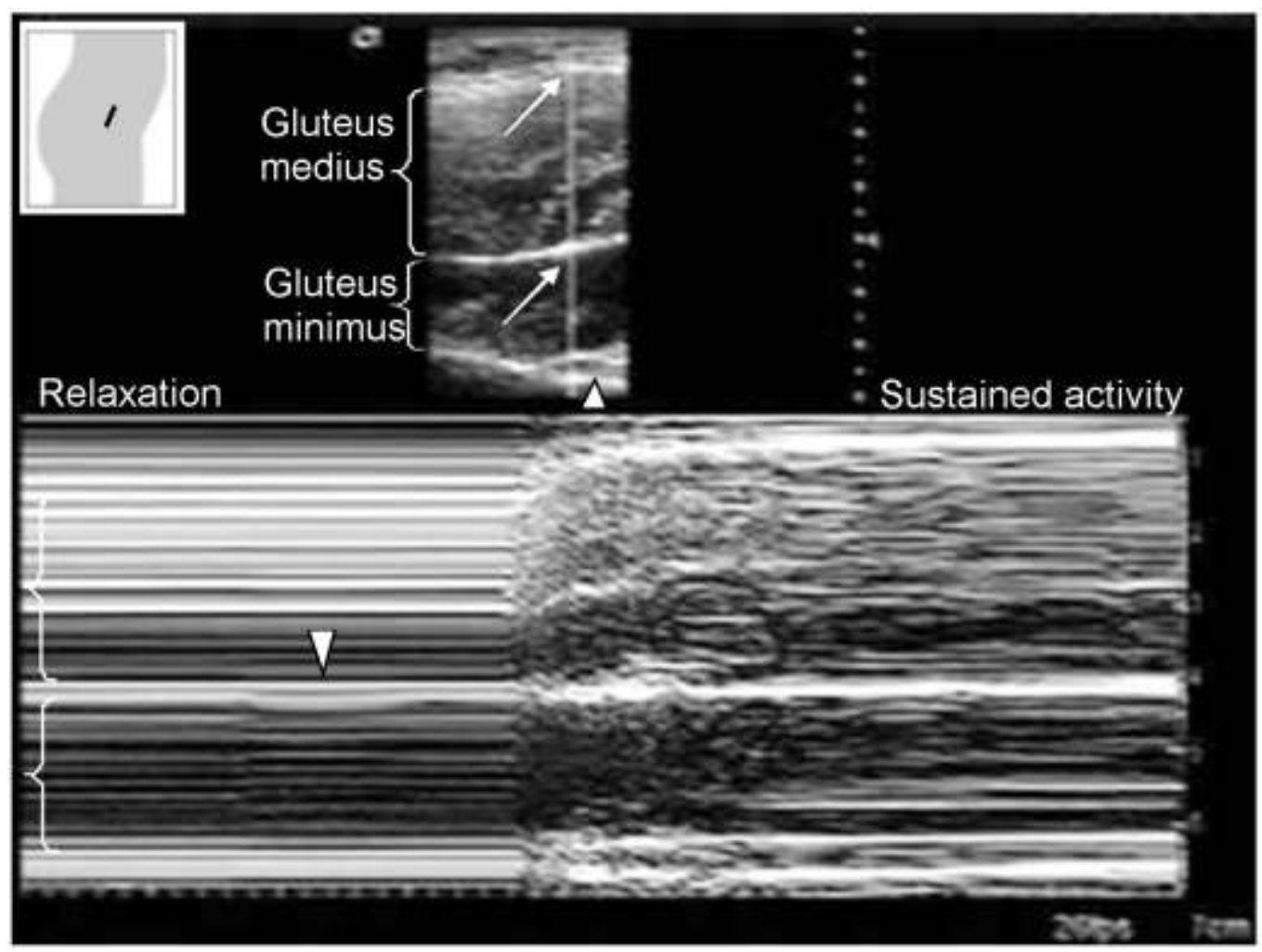

Figure 2. M-mode trace of the onset of isometric abductor activity. Muscle relaxation before activity is indicated by undisturbed horizontal lines, pulsation of a vessel is detectible as slight line displacement in gluteus minimus (larger arrowhead).

5 Sustained activity can be distinguished from relaxation by less stable M-mode lines. Arrows point at the angles of the M-mode sound-beam towards the gluteus medius fascia and aponeurosis which were measured to assess angle variation. Smaller arrowhead indicates reflected head of rectus femoris in the B-mode image. 
Ultrasound imaging of hip abductors

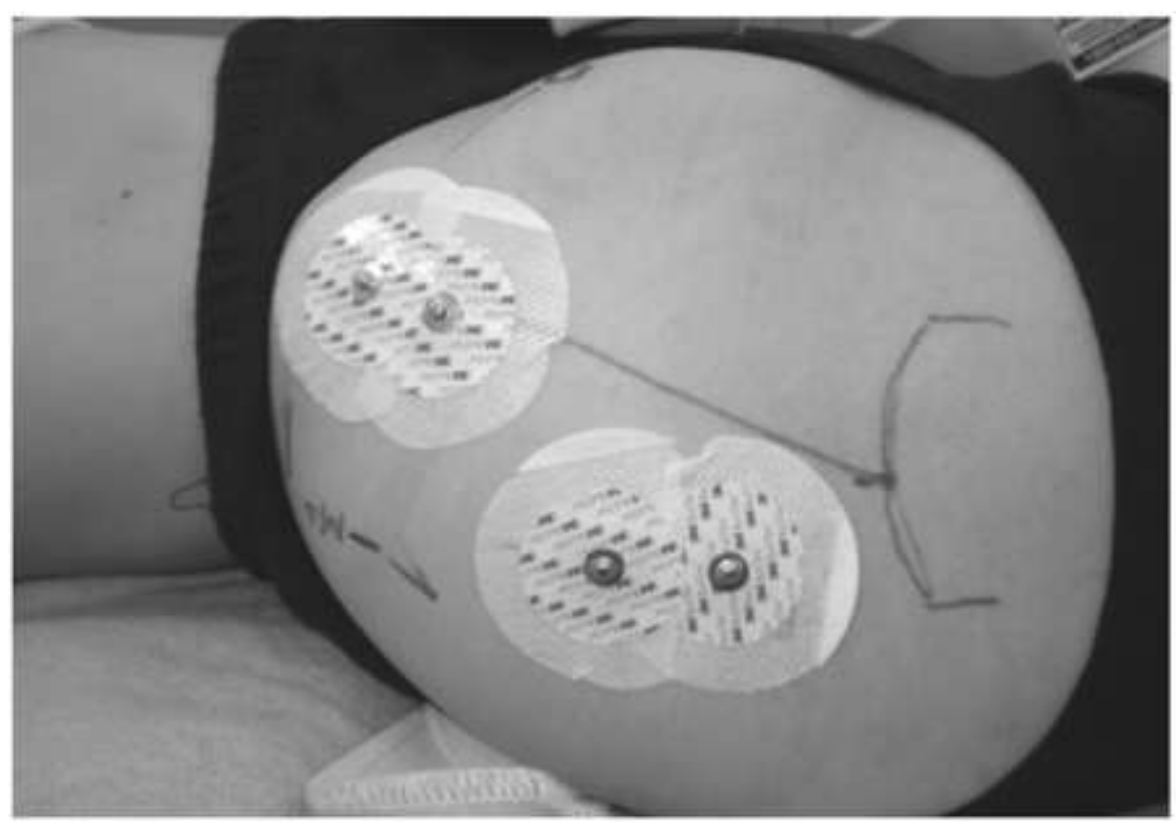

Figure 3. Reference line connecting the tip of the greater trochanter to the anterior quarter of a line between ASIS and PSIS, surface electrode positions. The US transducer was positioned on the lower half of the reference line. 
Ultrasound imaging of hip abductors

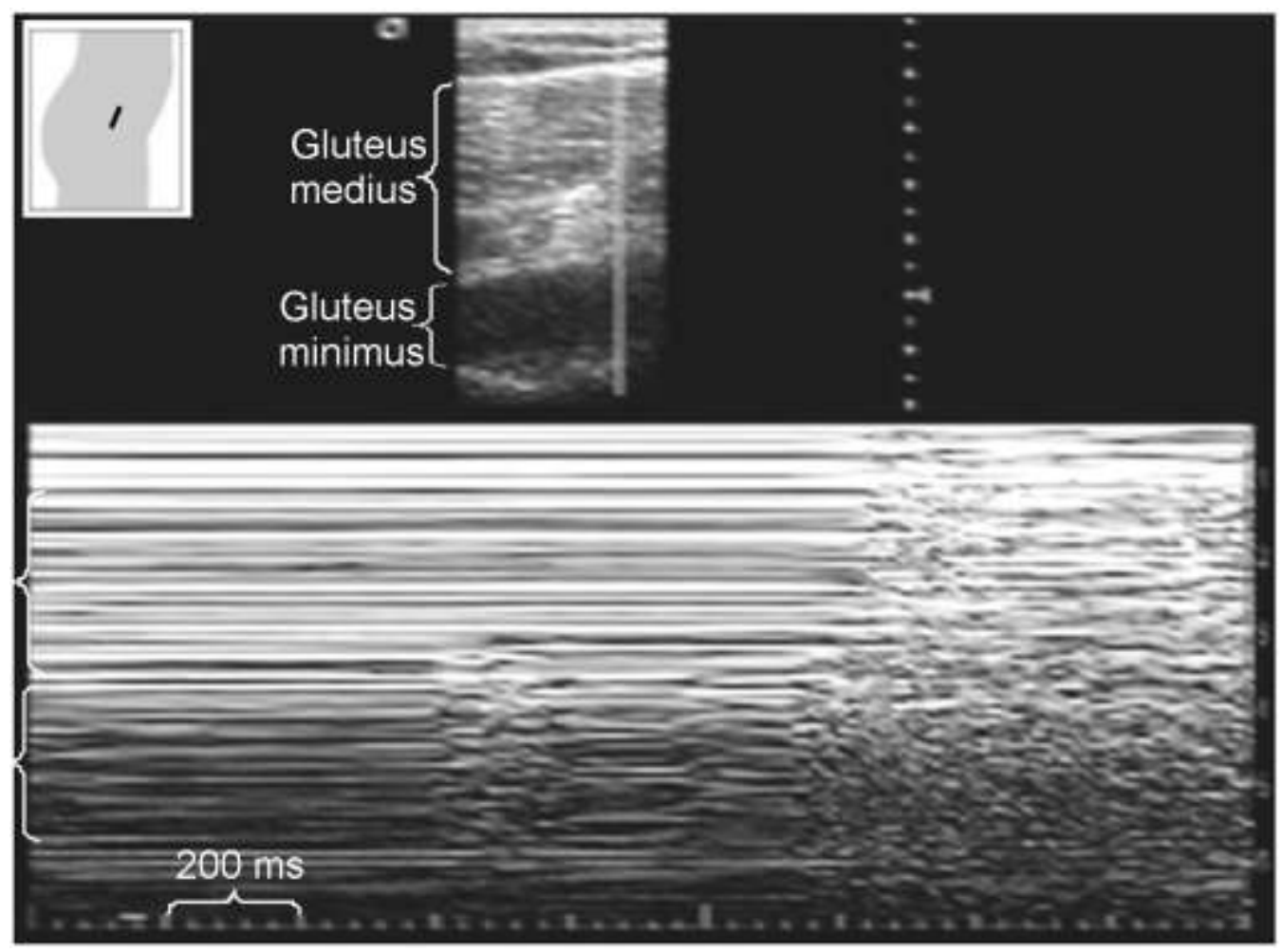

Figure 4. Isolated gluteus minimus motion that preceded the activity of gluteus medius by $640 \mathrm{~ms}$. 